\title{
Rindopepimut: an evidence-based review of its therapeutic potential in the treatment of EGFRvIll-positive glioblastoma
}

This article was published in the following Dove Press journal:

Core Evidence

13 September 2012

Number of times this article has been viewed

\author{
Ranjith Babu \\ D Cory Adamson \\ Division of Neurosurgery, \\ Department of Surgery, Duke \\ University Medical Center, \\ Durham, NC, USA
}

\begin{abstract}
Glioblastoma multiforme (GBM) is the most common primary brain tumor in adults and is universally fatal. Despite surgical resection, radiotherapy, and systemic chemotherapy, the median overall survival is less than 15 months. As current therapies are not tumor-specific, treatment commonly results in toxicity. The epidermal growth factor receptor variant III (EGFRvIII) is a naturally occurring mutant of EGFR and is expressed on approximately $20 \%$ to $30 \%$ of GBMs. As it is not expressed on normal cells, it is an ideal therapeutic target. Rindopepimut is a peptide vaccine which elicits EGFRvIII-specific humoral and cellular immune responses. Phase I and II clinical trials have demonstrated significantly higher progression-free and overall survival times in vaccinated patients with EGFRvIII-expressing GBM tumors. Side effects are minimal and mainly consist of hypersensitivity reactions. Due to the efficacy and safety of rindopepimut, it is a promising therapy for patients with GBM. Currently, rindopepimut is undergoing clinical testing in an international Phase III trial for newly diagnosed GBM and a Phase II trial for relapsed GBM.
\end{abstract} Keywords: CDX-110, EGFRvIII, glioblastoma, immunotherapy, PEPvIII

Core evidence clinical impact summary for rindopepimut for EGFRvIII-positive glioblastoma

\begin{tabular}{|c|c|c|}
\hline Outcome measure & Evidence & Implications \\
\hline \multicolumn{3}{|c|}{ Disease-oriented evidence } \\
\hline $\begin{array}{l}\text { Induction of cellular } \\
\text { and humoral } \\
\text { immune responses }\end{array}$ & $\begin{array}{l}\text { Preclinical, phase I (VICTORI: } \mathrm{N}=12 \text { ) } \\
\text { and phase II } \\
\text { (ACTIVATE: } \mathrm{N}=18 ; \text { ACT II: } \mathrm{N}=22 \text {; } \\
\text { ACT III: } \mathrm{N}=65 \text { ) } \\
\text { studies demonstrating the induction } \\
\text { of EGFRvIll- } \\
\text { specific cellular and humoral immune } \\
\text { responses }\end{array}$ & $\begin{array}{l}\text { Vaccination results in specific } \\
\text { antitumoral activity towards } \\
\text { EGFRvIll-expressing cells } \\
\text { with no cross-reactivity with } \\
\text { normal cells }\end{array}$ \\
\hline \multicolumn{3}{|c|}{ Patient-oriented evidence } \\
\hline $\begin{array}{l}\text { Progression-free } \\
\text { survival (PFS) }\end{array}$ & $\begin{array}{l}\text { Multicenter phase II clinical trials } \\
\text { demonstrating significantly higher } \\
\text { PFS compared to historic controls } \\
\text { and previous phase III clinical trials } \\
\text { when added to the } \\
\text { current standard of care } \\
\text { - ACTIVATE (I } 4.2 \text { vs } 6.3 \text { months } \\
\text { (matched cohort)) } \\
\text { - ACT II (I5.2 vs } 6.3 \text { months } \\
\text { (historical cohort)) } \\
\text { - ACT III (I } 2.3 \text { vs } 6.3 \text { months } \\
\text { (historical cohort)) }\end{array}$ & $\begin{array}{l}\text { Significantly improves patient quality } \\
\text { of life and overall survival }\end{array}$ \\
\hline
\end{tabular}

(Continued)
Correspondence: Cory Adamson Division of Neurosurgery, DUMC 2624,

Durham, NC 277I0, USA

$\mathrm{Tel}+19196983152$

Fax + I 9196845483

Email cory.adamson@duke.edu 


\begin{tabular}{|c|c|c|}
\hline \multicolumn{3}{|l|}{ (Continued) } \\
\hline Outcome measure & Evidence & Implications \\
\hline Overall survival & $\begin{array}{l}\text { Multicenter phase II clinical trials } \\
\text { demonstrating } \\
\text { significantly higher overall survival } \\
\text { compared to historic } \\
\text { controls and previous phase III clinical } \\
\text { trials when added } \\
\text { to the current standard of care } \\
\text { - ACTIVATE ( } 26.0 \text { vs I5.0 months } \\
\text { (matched cohort)) } \\
\text { - ACT II ( } 23.6 \text { vs I } 5.0 \text { months } \\
\text { (historical cohort)) } \\
\text { - ACT III }(24.6 \text { vs } 15.0 \text { months } \\
\text { (historical cohort)) }\end{array}$ & $\begin{array}{l}\text { Significantly improves patient } \\
\text { survival and supports its use for } \\
\text { EGFRvIll-expressing glioblastoma } \\
\text { multiformus }\end{array}$ \\
\hline Safety & $\begin{array}{l}\text { Phase I (VICTORI: } \mathrm{N}=12 \text { ) and II } \\
\text { (ACTIVATE: } \mathrm{N}=18 \text {; } \\
\text { ACT II: } \mathrm{N}=22 ; \mathrm{ACT} \text { III: } \mathrm{N}=65 \text { ) } \\
\text { studies demonstrating } \\
\text { minimal adverse effects which mainly } \\
\text { consisted of } \\
\text { reactions that were not more severe } \\
\text { than grade II toxicity }\end{array}$ & $\begin{array}{l}\text { Allows for the safe use in patients } \\
\text { due to no evidence of significant } \\
\text { autoimmunity as a result of } \\
\text { vaccination }\end{array}$ \\
\hline \multicolumn{3}{|l|}{ Economic evidence } \\
\hline Cost-effectiveness & $\begin{array}{l}\text { Unknown as rindopepimut has not yet } \\
\text { received marketing authorization }\end{array}$ & \\
\hline
\end{tabular}

\section{Introduction}

Glioblastoma multiforme (GBM) is the most common primary brain tumor in adults. These tumors are classified by the World Health Organization (WHO) as grade IV gliomas and are highly aggressive, with recurrence occurring in all cases. Despite surgical resection, radiotherapy, and systemic chemotherapy, the median overall survival (OS) is less than 15 months. ${ }^{1}$ Additionally, patients with recurrent tumors have an even worse prognosis. ${ }^{2,3}$ While current therapies are able to increase OS and progression-free survival (PFS), these therapies damage normal tissue and typically fail..$^{1,4,5}$ As a result, there is a need for more specific and effective therapies which are able to selectively target tumor cells without damaging normal brain cells.

Immunotherapy has become an attractive therapeutic modality. The identification of tumor-associated antigens has allowed for the manipulation of the immune system to eliminate neoplastic cells without affecting normal parenchyma. ${ }^{6}$ Currently, a variety of immunotherapies have been approved for the treatment of various cancers, with many in advanced clinical trials. These treatments are composed of cellular and recombinant components that utilize innate and adaptive immune responses. Immunotherapies consist of immune-modulating and tumor-specific antibodies, adoptive cell transfer, and cancer vaccines. ${ }^{7}$
While tumor-specific monoclonal antibodies such as rituximab and trastuzumab are the highest grossing cancer therapies, there is increasing interest in the use of vaccines to activate the immune system against tumor antigens. One such target in GBM is the mutated epidermal growth factor receptor variant III (EGFRvIII), which is a tumor-specific epitope expressed on approximately $20 \%-30 \%$ of GBMs, $78 \%$ of breast carcinomas, $73 \%$ of ovarian carcinomas, $42 \%$ of head and neck squamous cell carcinomas, and 39\% of nonsmall-cell lung cancers. ${ }^{8-14}$ EGFRvIII expression typically occurs in the presence of wild-type EGFR overexpression, occurring in $58 \%$ to $65 \%$ of such cases. ${ }^{8,15,16}$ As wild-type EGFR overexpression most frequently occurs in primary (de novo) GBM and rarely in secondary GBM (those that progress from low-grade tumors), EGFRvIII expression is most common in primary tumors. ${ }^{17,18}$ Also some studies have demonstrated a male predominance for EGFRvIII expression in GBM. ${ }^{8,19}$ While EGFRvIII has various oncogenic effects, its expression in GBM has not been seen to significantly affect survival compared to those who only express wild-type EGFR. ${ }^{8,16,19}$ EGFRvIII contains an in-frame deletion of 801 base pairs from the extracellular domain of EGFR, resulting in the fusion of two distant portions of the molecule (Figure 1). This creates an antigenic junction with a novel glycine residue. ${ }^{20,21}$ This constitutively active, 


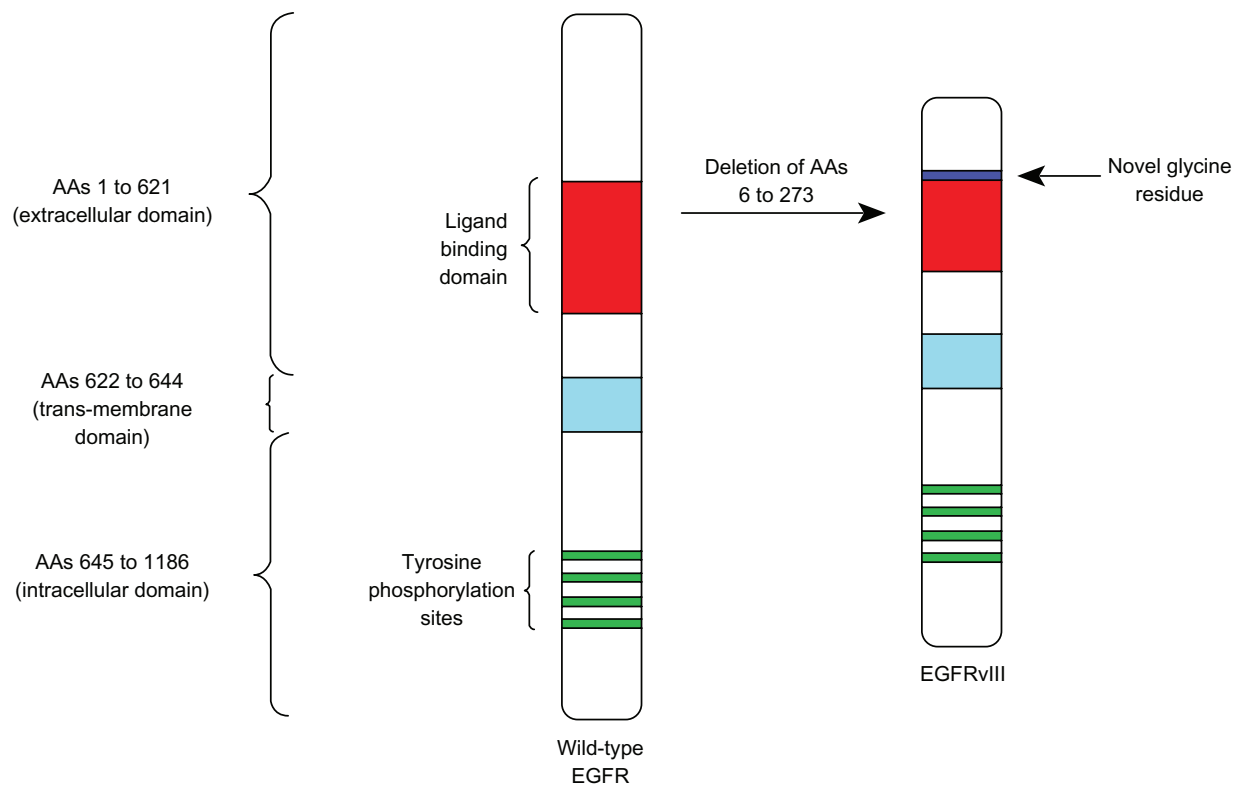

Figure I Schematic showing a deletion of amino acids 6 to 273 and an insertion of a novel glycine residue in the extracellular domain of wild-type EGFR, forming EGFRvill.

Abbreviations: EGFR, epidermal growth factor receptor; vlll, variant III.

ligand-independent mutant enhances tumorigenicity, tumor cell migration, and resistance to chemoradiotherapy. ${ }^{22-27}$

As it is not expressed on normal cells, EGFRvIII is an effective target for immunotherapies. ${ }^{10,14}$ One such therapy is rindopepimut (PEPvIII-KLH; CDX-110; Celldex Therapeutics, Phillipsburg, NJ), an EGFRvIII-specific, 14-mer peptide which when coupled with keyhole limpet hemocyanin (KLH) elicits humoral and cellular immune responses. ${ }^{28,29}$ Currently, rindopepimut is undergoing clinical testing in a Phase III trial for newly diagnosed GBM (NCT01480479), a Phase II trial with granulocytemacrophage colony-stimulating factor (GM-CSF) for relapsed GBM (NCT01498328), and a Phase I trial for use in children with diffuse intrinsic pontine gliomas (NCT01058850). This review summarizes the current evidence for the use of rindopepimut in GBM.

\section{Barriers to immunotherapy for brain tumors}

For immunotherapies to initiate immune responses, CD4+ (helper) and CD8+ (cytotoxic) $\mathrm{T}$ cells must be activated by the recognition of antigens on the class I or II major histocompatibility complexes (MHCs) found on antigen-presenting cells (APCs) ${ }^{30}$ However, full activation only occurs following a co-stimulatory signal between T cells and APCs. The absence of this signal, which is necessary for $\mathrm{T}$ cell proliferation and differentiation, results in anergy or cell death.

Several challenges are present for the use of immunotherapy for intracerebral tumors. Firstly, the brain is considered to be immunologically isolated compared to other organs. This was suggested by studies showing that intracranially implanted tissue grafts in animals did not result in rejection. ${ }^{31}$ This is thought to be due to the absence of lymphatic architecture, the presence of the blood-brain barrier (BBB), and paucity of APCs within the brain. ${ }^{32,33}$ However, more recent studies have shown that the brain is not as isolated as previously thought. While there are no draining lymph nodes in the brain, antigens within the central nervous system (CNS) can drain in the cerebrospinal fluid (CSF) through Virchow-Robin spaces to cervical and nasal lymph nodes. ${ }^{34-36}$ Also though the BBB was thought to limit leukocyte movement into the $\mathrm{CNS}$, numerous studies have demonstrated lymphocyte BBB penetration. ${ }^{37-39}$ Activated T cells highly express molecules such as leukocytefunction-associated antigen-1 (LFA-1) and very late antigen-4 (VLA-4) which allow for their migration across the BBB. ${ }^{40-42}$ The production of inflammatory mediators by the peripheral immune system can also increase the permeability of the $\mathrm{BBB}$, allowing for activated macrophages and dendritic cells (DCs) to enter the CNS. Other mechanisms of leukocyte entry into the CNS include transmigration via transient pore-like structures within the endothelial cells of the BBB, and extravasation across the fenestrated endothelium of the choroid plexuses. ${ }^{43-46}$ Additionally, BBB composition has been shown to vary between different brain regions, resulting in various degrees of cellular immune surveillance. ${ }^{47}$ Finally, while there is not an abundance of APCs within the CNS, macrophages, DCs, and microglia can act as effective APCs to stimulate T-cell responses. ${ }^{48-50}$ As studies have demonstrated 
microglial density to differ by up to one order of magnitude in various brain regions, response to immunotherapies may also be location-dependent. ${ }^{51}$

In addition to the barriers posed by the normal brain, GBM cells elicit responses that often make development of treatments challenging (Figure 2). Patients with GBM have been shown to have systemic immune deficits, with lymphopenia of natural killer (NK) and CD4+ T cells, and dysregulation of cytokine profiles. ${ }^{52-56}$ Additionally, leukocyte impairments have been reported including decreased T- and B-cell proliferation, antigen presentation, cytokine and antibody production, and NK cell cytotoxicity. These effects are thought to be partly due to the secretion of molecules such as transforming growth factor- $\beta$ (TGF- $\beta$ ), interleukin-10 (IL-10), prostaglandin $\mathrm{E}_{2}\left(\mathrm{PGE}_{2}\right)$, and gangliosides. ${ }^{57}$ Additionally, GBM cells express a multitude of immunosuppressive molecules, preventing the anti-tumor activity of leukocytes. The expression of the co-stimulatory inhibitory molecule B7-H1 on GBM-associated cancer-initiating cells triggers $\mathrm{T}$ cell apoptosis. ${ }^{58,59}$ HLA-G, a nonclassical MHC class I molecule, is also expressed on GBM cells and can prevent the efficient priming of cytotoxic $\mathrm{T}$ cells, inhibit alloproliferative responses, and increase resistance to alloreactive lysis. ${ }^{60}$ Similarly, the expression of CD70 on GBM cells results in T- and B-cell apoptosis via the interaction with CD27. ${ }^{61}$ Another contributor to immunosuppression in patients with GBM is the increased levels of CD4+/CD25+ $\mathrm{T}_{\text {regs }}$ despite systemic lymphopenia. ${ }^{62}$ These cells are attracted to the tumor environment in high-grade astrocytic tumors due to the secretion of CCL2, and result in the inhibition of T cell cytokine secretion and proliferation. ${ }^{63-65}$ As a multitude of mechanisms contribute to immunosuppression in patients with GBM, a multimodal approach is necessary to reduce the immunosuppressive effects of the tumor microenvironment, and enhance the ability to mount an effective immune response within the CNS.

\section{EGFRvIII as an immunotherapeutic target}

EGFR is a transmembrane glycoprotein which contains an extracellular ligand-binding domain and a cytoplasmic domain containing a tyrosine kinase. ${ }^{66}$ It is activated upon binding of its ligands including the epidermal growth factor (EGF) or TGF $\alpha$, resulting in receptor dimerization and activation of the tyrosine kinase domain. This turns on oncogenic pathways which may account for the poorer survival seen in GBM patients with EGFR amplification. ${ }^{67}$ This amplification and resulting overexpression of the EGFR protein is the most common genetic alteration in GBM, occurring in approximately $40 \%$ of

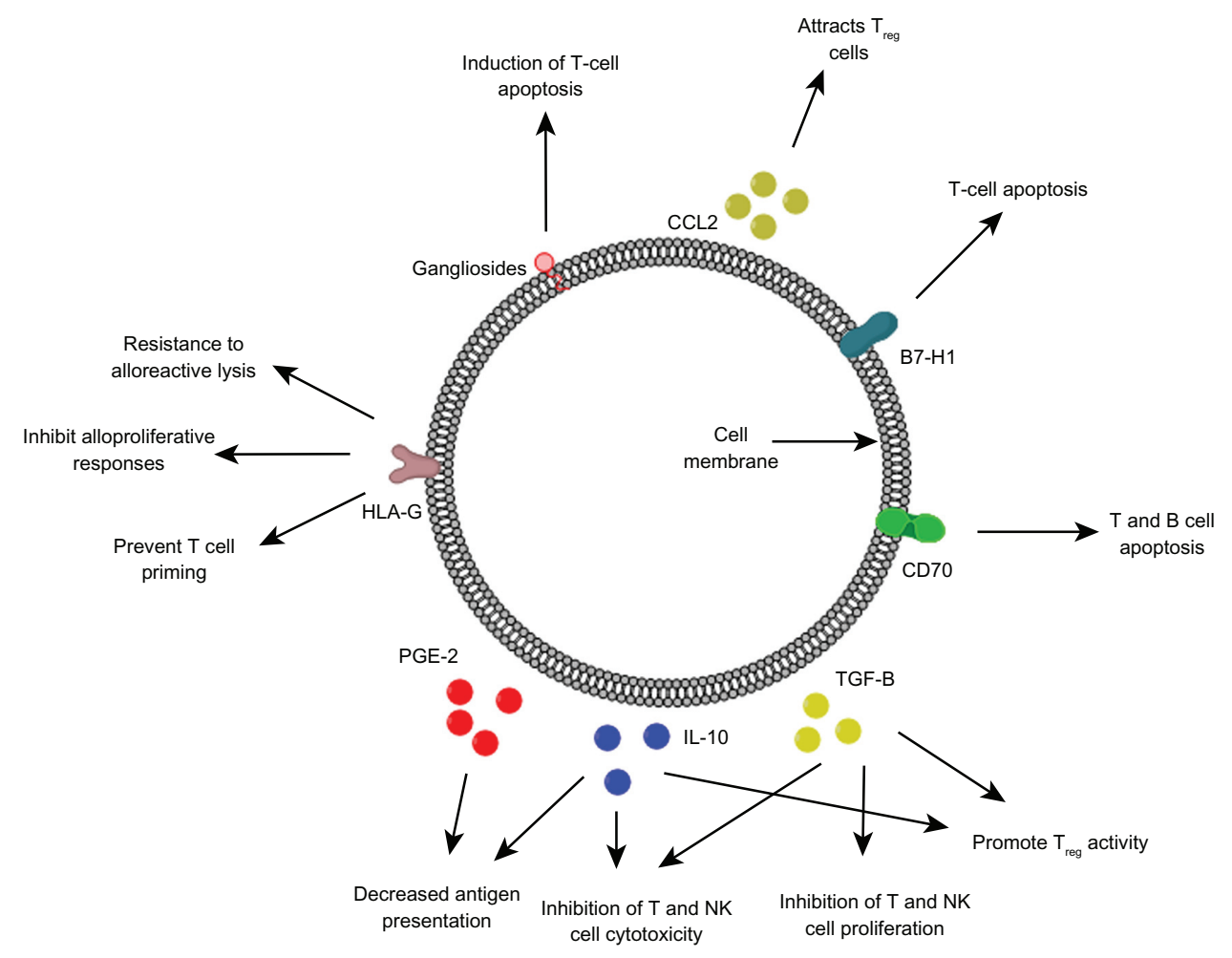

Figure 2 Various immunosuppressive factors expressed and secreted by glioblastoma cells. 
newly diagnosed cases. ${ }^{67,68}$ In tumors that overexpress EGFR, up to $75 \%$ of cases have rearrangements of the EGFR gene that lead to the expression of mutant forms..$^{15,69-72}$ The most common EGFR mutation is EGFRvIII which results from an in-frame deletion of 267 amino acids in the extracellular domain (Figure 1). ${ }^{73}$ This receptor has constitutive tyrosine kinase activity and has important pro-oncogenic effects including enhancing proliferation, radio- and chemotherapeutic resistance, and migration, while inhibiting apoptosis. ${ }^{22-27,74,75}$ While $37 \%-86 \%$ of cells within EGFRvIII-expressing tumors express this receptor, EGFRvIII positive cells are able to secrete membrane-derived microvesicles with EGFRvIII which then merge with the plasma membranes of negative cells, conferring the same oncogenic advantages. ${ }^{76,77}$ As EGFRvIII contains an antigenic junction with a novel glycine residue and is not expressed on normal tissues, it is an effective target for immunotherapy. ${ }^{12}$

A variety of immunotherapies targeting EGFRvIII are currently under investigation including monoclonal antibodies, dendritic cell vaccination therapy, genetically modified $\mathrm{T}$ cells, and peptide vaccines. Various naked monoclonal antibodies have been shown to be specific for EGFRvIII and are able to elicit antitumor activity via Fc- and Fab-mediated activity. ${ }^{78-82}$ Monoclonal antibodies conjugated to toxins have also demonstrated significant cytotoxic activity against EGFRvIII-expressing tumors. ${ }^{83,84}$ Dendritic cell vaccination utilizes the antigen-presenting properties of dendritic cells to initiate antitumor responses. In vivo and human studies have demonstrated peptide-pulsed dendritic cells to induce EGFRvIII-specific cell-mediated immunity. ${ }^{85}$ More recently, genetically engineered $\mathrm{T}$ cells which express chimeric immune receptors have been shown to specifically lyse EGFRvIII-expressing gliomas cells in in vitro and in vivo studies. ${ }^{86}$ While these therapies are all attractive therapeutic modalities, peptide vaccines are one of the most studied and well understood immunotherapies. The most promising peptide vaccinate utilizes a peptide derived from the novel fusion junction amino acid sequence of EGFRvIII. This vaccine consists of PEPvII (H-Leu-Glu-Glu-Lys-LysGln-Asn-Tyr-Val-Val-Thr-Asp-His-Cys-OH), an EGFRvIIIspecific 14-mer peptide, and $\mathrm{KLH}^{28}$ As it is able to activate humoral and cellular immunoreactivity, and has been shown to induce EGFRvIII-specific immune responses in preclinical and clinical studies. ${ }^{29,87-89}$

\section{Detection of EGFRvIII mutations}

Due to the potential prognostic and therapeutic importance of EGFRvIII, its efficient detection is necessary for both laboratory and clinical evaluation. As one of the most common methods of tissue preservation is formalin fixation plus paraffin embedding (FFPE), immunohistochemistry (IHC) is widely used as an accurate and reliable method for detecting EGFRvIII expression in stored samples. ${ }^{8,10,19,90,91}$ A variety of monoclonal and polyclonal antibodies have been developed which specifically recognize EGFRvIII and are commonly used for evaluating its expression in clinical studies. EGFRvIII can also be detected in fresh frozen and FFPE tissue using real-time reverse transcription-polymerase chain reaction (RT-PCR) and Southern blot assays. ${ }^{90,91}$

\section{Preclinical studies}

Monoclonal antibodies targeted to EGFRvIII have shown to exhibit effective antitumor activity in in vitro and in vivo models. Treatment with unarmed murine IgG2a (Y10) and IgG1 (L8A4) monoclonal antibodies targeting EGFRvIII significantly inhibited tumor growth, though only treatment with IgG2a resulted in tumor-free survival after treatment was discontinued. ${ }^{82}$ Though intraperitoneal therapy did not increase the median survival of mice with intracranial EGFRvIII B16 melanomas, single intratumoral injections of Y10 increased survival by $286 \%$, with $26 \%$ of mice becoming long-term survivors $(P<0.001)$. The in vivo mechanism of action of 10 was seen to be Fc receptor-dependent while being independent of T cells, NK cells, granulocytes, and complement.

Immunotherapy using PEPvIII-KLH has also been effective against intracranial EGFRvIII-expressing tumors. Immunization of mice with DCs mixed with PEPvIII-KLH resulted in an approximately 600\% increase in median survival, with $63 \%$ becoming long-term survivors. ${ }^{92}$ Also treatment with this mixture resulted in long-lasting protection as all rechallenged mice survived. Immunization with DCs mixed with PEPvIII-KLH produced EGFRvIII-specific IgG2a antibodies, correlating with antitumor activity. Another study demonstrated that a single dose of PEPvIII-KLH in Freund's complete adjuvant increased median survival by $26 \%$ in mice with EGFRvIII-expressing intracerebral tumors $(P=0.0076) .{ }^{89}$ It was also seen that EGFRvIII expression was lost in $80 \%$ of relapsing tumors after vaccination, suggesting that EGFRvIII-negative escape is a potential mechanism of treatment failure (wild-type EGFR status was unknown in this study). Vaccination with PEPvIII-KLH resulted in humoral responses that could mediate antibody-dependent cellular cytotoxicity (ADCC), with the transfer of serum from vaccinated mice inducing antitumoral activity. The efficacy of PEPvIII-KLH was also seen to be dependent on CD8+ T and NK cells. 


\section{Clinical studies}

Due to the success of PEPvIII-KLH in in vivo studies, several clinical trials were designed. The first clinical trial (Phase I; VICTORI) was conducted at the Duke University Medical Center and enrolled 15 adults with newly diagnosed GBM. ${ }^{87}$ However, as three patients had tumor progression during external beam radiotherapy and were not vaccinated, the data of 12 patients were analyzed. The median age was 42 years, with the majority of patients (58.3\%) having a KPS of 100 (mean: 95.8). Patients underwent leukapheresis to obtain peripheral blood mononuclear cells (PBMC) for the generation of DCs and immunologic monitoring. DCs were then pulsed with PEPvIII-KLH and administered intradermally every 2 weeks at doses up to $1.1 \times 10^{8} \mathrm{DCs}$ in three equal doses. Patients were monitored for tumor progression and toxicity. There were no cases with serious adverse effects beyond grade II toxicity. While patients had increased erythrocyte sedimentation rate and rheumatoid factor levels, these increases were minimal and did not result in clinical symptoms. Immunization was seen to induce antigen-specific cellular and humoral immune responses (as detected ex vivo). The median time to progression was 10.2 months ( $95 \%$ confidence interval [CI]: 5.7-12.6) and median survival was 22.8 months (95\% CI: 17.5-29). Patient survival was compared to that based on recursive partition analysis. ${ }^{93}$ Of the 12 trial patients, eight were in group III, with the remaining in group IV. As patients in these groups have an expected survival of 17.9 and 11.1 months, respectively, nine of 12 study patients were seen to exceed these expectations. While this difference did not reach statistical significance $(P=0.083)$, the results may have been negatively biased as EGFRvIII expression was not a criterion for inclusion.

The promising results of PEPvIII-KLH in the Phase I toxicity trial led to the initiation of a second clinical trial. Due to the expense and variability associated with the use of DCs, further studies only administered PEPvIIIKLH in combination with GM-CSF. The second trial, A Complimentary Trial of an Immunotherapy Vaccine Against Tumor Specific EGFRvIII (ACTIVATE), was performed at the Duke University Medical Center and MD Anderson Cancer Center. ${ }^{88}$ Eighteen patients with newly diagnosed EGFRvIII expressing GBM (as detected via immunohistochemistry on paraffin-embedded tissue) having a gross total resection $(>95 \%$ ), Karnofsky performance status (KPS) $\geq 80$, and not exhibiting radiographic progression following external beam radiotherapy and concurrent temozolomide were included in the trial. The median age of the cohort was 52 years, with a mean KPS of 91.7. Patients were intradermally

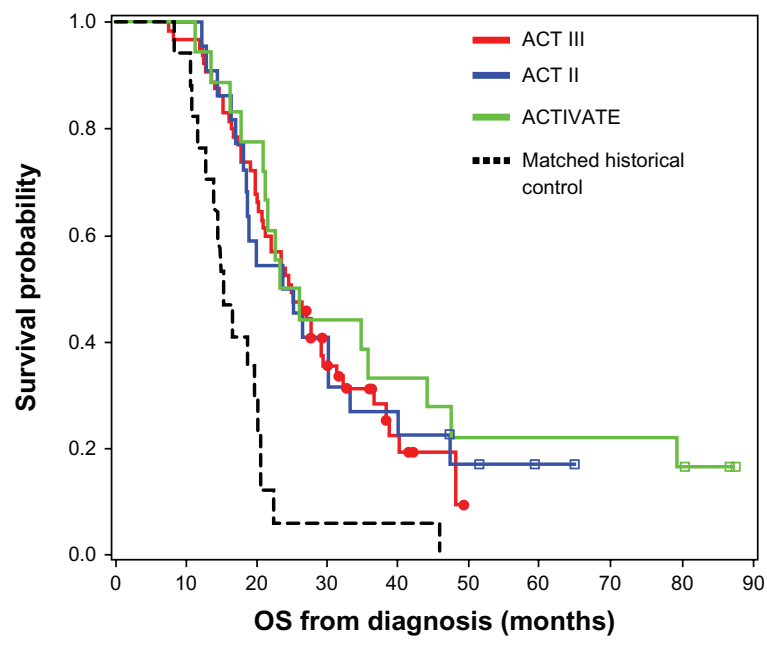

Figure 3 Kaplan-Meier overall survival curves showing higher overall survival in vaccinated patients in each of the Phase II clinical trials.

Note: Lai RK, Recht LD, Reardon DA, et al. Long-term follow-up of ACT III: A Phase II trial of rindopepimut (CDX-II0) in newly diagnosed glioblastoma. Neuro Oncol. 201 I; I3(Suppl 3): iii34-iii40, by permission of Oxford University Press. ${ }^{95}$

administered PEPvIII-KLH/CDX-110 in GM-CSF, receiving three vaccinations every 2 weeks and monthly thereafter until progression. Toxicity was mostly limited to injection site reactions and was never more severe than grade II toxicity. One patient developed asymptomatic areas of T2-signal hyperintensity which was thought to be grade I leukoencephalopathy toxicity. The median time to progression was 14.2 months and median OS was 26.0 months. This survival was significantly better than that seen in a temozolomide-treated matched control group (hazard ratio [HR]: $5.1 ; 95 \%$ CI: $1.9-13.9 ; P=0.001$ ) (Figure 3). As seen in the in vivo studies, the majority of recurrent tumors (82\%) had lost EGFRvIII expression at recurrence. The serum of 14 patients was analyzed for EGFRvIII-specific humoral responses, with six inducing such a response. The median OS of patients who developed EGFRvIII-specific antibody responses was 47.7 months, compared to 22.8 months in those who did not develop antibody responses $(P=0.025)$. Assessment of cellular immune responses showed three of 17 patients to have a positive delayed-type hypersensitivity (DTH) response. Patients who developed PEPvIII-specific DTH responses had a significantly longer PFS and OS $(P=0.03)$.

A third clinical trial (Phase II; ACTII) was designed to assess the efficacy of PEPvIII-KLH with standard-dose (STD) and dose-intensified (DI) temozolomide regimens in 22 patients. ${ }^{94}$ Patients in group A were assigned to receive temozolomide at a dose of $200 \mathrm{mg} / \mathrm{m}^{2}$ for 5 days of a 28 day cycle, with those in group B receiving $100 \mathrm{mg} / \mathrm{m}^{2}$ for 21 days of a 28 day cycle. Immunization with PEPvIII-KLH 
with GM-CSF was performed on day 21 of each 28-day temozolomide cycle. The mean cohort age was 57 years, with most patients (64\%) having a KPS of 100 . There was minimal toxicity, with no significant elevations in autoimmunity markers and no development of new T2 abnormalities. All immunized patients developed EGFRvIII-specific humoral responses, with only patients in the DI group having DTH responses. Interestingly, despite inducing more severe lymphopenia, treatment with DI temozolomide enhanced humoral and cellular immune responses following vaccination compared to STD temozolomide. As previously seen, 91.6\% of recurrent tumors had lost expression of EGFRvIII. The median PFS was 15.2 months, with patients having a median OS of 23.6 months. These outcomes were significantly better than historical controls, with survival significantly exceeding the survival expectations of Curran's recursive partitioning analysis $(P<0.0001)$ and the EORTC 26981/22981-NCIC CE3 Phase III randomized trial $(P=0.008)$ (Figure 3$)$.

Another Phase II trial (ACTIII) to study the efficacy of PEPvIII-KLH/rindopepimut in a larger population of newly diagnosed GBMs was then initiated. ${ }^{95}$ This study enrolled 65 patients, with therapy including temozolomide maintenance therapy $\left(150-200 \mathrm{mg} / \mathrm{m}^{2}\right.$ for $5 / 28$ days) and three vaccinations every 2 weeks and then on the 21 st day of each temozolomide cycle monthly (Figure 4). The median age was 56 years, with studied patients having a median KPS of 90. Toxicity in this trial included grade I-II injection site reactions, a grade II hypersensitivity reaction, and a case with grade III toxic epidermal necrolysis. The median PFS was 12.3 months and OS was 24.6 months, both of which were significantly higher than historical controls $(P=0.0088$ and $<0.0001$, respectively) (Figure 3). As expected, patients with methylated MGMT had a significantly higher PFS (17.5 vs 11.2 months; $P=0.0057)$ and OS (32.3 vs 20.9 months; $P=0.0067$ ).

\section{Ongoing clinical trials}

Currently there are two active trials investigating the use of rindopepimut in GBM. A Phase III trial (ACT IV) has been initiated to investigate the safety and efficacy of rindopepimut in newly diagnosed GBM (Figure 3). This international trial is being conducted at over 100 centers and will include $\sim 374$ patients with a gross total resection. Additionally, patients having incomplete resections will be enrolled, allowing for the evaluation of rindopepimut efficacy in patients with residual tumor burden. All patients will only receive two priming vaccines (compared to three in previous trials). The estimated completion date is November 2016. Another Phase II trial (ReACT) is investigating the efficacy of rindopepimut in combination with bevacizumab in patients with relapsed EGFRvIII-positive GBM. Patients will be enrolled into two groups: Group 1 patients will be randomly assigned to receive either rindopepimut or KLH, each with bevacizumab; Group 2 patients will all be treated with rindopepimut in combination with bevacizumab and consists of those refractory to bevacizumab. The primary outcome measure is PFS rate at 6 months, with secondary outcomes being safety and tolerability, antitumor activity, and EGFRvIII-specific immune response. As tumor volume is not an exclusion criterion in this trial, the efficacy of rindopepimut in cases with significant tumor burden will also be evaluated. This study will seek to enroll 95 patients and has an estimated primary completion date of March 2014.

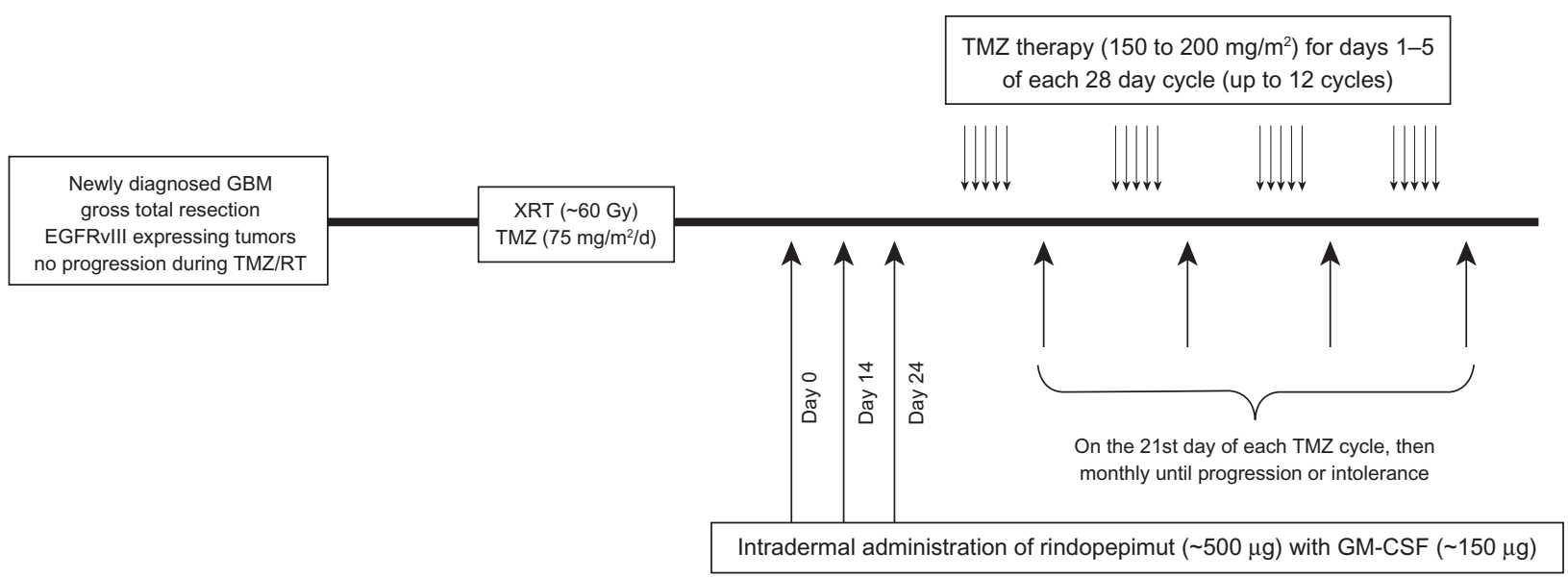

Figure 4 Timeline demonstrating the schedule of treatment for glioblastoma patients undergoing immunotherapy with rindopepimut. Abbreviation: GBM, glioblastoma multiforme. 


\section{Limitations}

While rindopepimut is efficacious and safe for the treatment of GBM, there are several limitations. Firstly, as EGFRvIII is only expressed in a small number of GBMs $(\sim 20 \%-30 \%)$, rindopepimut cannot be used to treat the majority of GBM cases. Therefore, immunotherapy directed toward other tumor-specific targets such as cytomegalovirus antigens may allow for more widespread use. Rindopepimut also has limited utility for the continued treatment of cases with tumor recurrence despite vaccine therapy as most of these tumors lose EGFRvIII expression. Additionally, the performed clinical trials have had several shortcomings. Firstly, all patients did not receive salvage therapy uniformly for tumor progression as the use of additional agents was the discretion of the patient's neurooncologist. This may introduce bias by affecting OS. The presence of isocitrate dehydrogenase 1/2 (IDH1/2) mutations was not determined in enrolled patients. These mutations which occur most commonly in secondary GBMs significantly predict survival and may confer a survival advantage. ${ }^{96-98}$ As a result, an overrepresentation of these mutations in the study cohort may artificially improve OS compared to historical controls. However, as EGFRvIII is rarely expressed in secondary GBMs, the effect of IDH1/2 mutations is likely minor as the ACTIVATE, ACTII, and ACTIII trials only enrolled patients with EGFRvIII-expressing tumors. In addition to the small sample sizes in the current studies, only patients with a high performance status and those not having evidence of disease progression following chemoradiotherapy were enrolled. These inclusion criteria result in the selection of patients having an overall better prognosis and thus introduce significant selection bias. Also, all patients underwent image verified gross total resections. This was intended to minimize the immunosuppressive effects of the tumor mass. As a significant percentage of GBM patients do not receive gross total resection, the efficacy of rindopepimut in these cases in unclear. The use of inhibitors to negate the effects of various immunosuppressive cascades such as the signal translation and activator of transcription-3 pathway may improve the efficacy of rindopepimut in cases with significant residual disease.

\section{Conclusion}

Rindopepimut (PEPvIII-KLH/CDX-110) is an effective EGFRvIII-targeted immunotherapy which appeared to improve PFS and OS in Phase I and II clinical trials for patients with EGFRvIII-expressing GBMs. Serious adverse reactions are rare, with patients typically only experiencing hypersensitivity reactions at the injection site. Currently, a Phase II trial for relapsed GBM and a Phase III trial for newly diagnosed cases are ongoing and will provide additional data regarding the efficacy of rindopepimut in the near future. While rindopepimut has limitations, it is a promising therapy for patients with EGFRvIII-expressing GBMs and significantly adds to our arsenal for combating this aggressive disease. There remains a paucity of approved immunotherapies in oncology (therapeutic one for prostate cancer and preventive one for cervical cancer), but we are optimistic that studies on therapies like rindopepimut will identify therapies that will prove efficacious in the general population.

\section{Disclosure}

The authors have no financial or institutional interest in any of the drugs, materials, or devices described in this article, or any other type of conflict of interest.

\section{References}

1. Stupp R, Mason WP, van den Bent MJ, et al. Radiotherapy plus concomitant and adjuvant temozolomide for glioblastoma. $N$ Engl $J$ Med. 2005;352(10):987-996.

2. Vredenburgh JJ, Desjardins A, Herndon JE 2nd, et al. Phase II trial of bevacizumab and irinotecan in recurrent malignant glioma. Clin Cancer Res. 2007;13(4):1253-1259.

3. Wong ET, Hess KR, Gleason MJ, et al. Outcomes and prognostic factors in recurrent glioma patients enrolled onto phase II clinical trials. J Clin Oncol. 1999;17(8):2572-2578.

4. Narayana A, Gruber D, Kunnakkat S, et al. A clinical trial of bevacizumab, temozolomide, and radiation for newly diagnosed glioblastoma. J Neurosurg. 2012;116(2):341-345.

5. Imperato JP, Paleologos NA, Vick NA. Effects of treatment on longterm survivors with malignant astrocytomas. Ann Neurol. 1990;28(6): $818-822$.

6. Rosenberg SA. Progress in human tumour immunology and immunotherapy. Nature. 2001;411(6835):380-384.

7. Topalian SL, Weiner GJ, Pardoll DM. Cancer immunotherapy comes of age. J Clin Oncol. 2011;29(36):4828-4836.

8. Heimberger AB, Hlatky R, Suki D, et al. Prognostic effect of epidermal growth factor receptor and EGFRvIII in glioblastoma multiforme patients. Clin Cancer Res. 2005;11(4):1462-1466.

9. Wong AJ, Ruppert JM, Bigner SH, et al. Structural alterations of the epidermal growth factor receptor gene in human gliomas. Proc Natl Acad Sci U S A. 1992;89(7):2965-2969.

10. Wikstrand CJ, Hale LP, Batra SK, et al. Monoclonal antibodies against EGFRvIII are tumor specific and react with breast and lung carcinomas and malignant gliomas. Cancer Res. 1995;55(14): 3140-3148.

11. Sok JC, Coppelli FM, Thomas SM, et al. Mutant epidermal growth factor receptor (EGFRvIII) contributes to head and neck cancer growth and resistance to EGFR targeting. Clin Cancer Res. 2006;12(17): 5064-5073.

12. Humphrey PA, Wong AJ, Vogelstein B, et al. Anti-synthetic peptide antibody reacting at the fusion junction of deletion-mutant epidermal growth factor receptors in human glioblastoma. Proc Natl Acad Sci U S A. 1990;87(11):4207-4211.

13. Okamoto I, Kenyon LC, Emlet DR, et al. Expression of constitutively activated EGFRvIII in non-small cell lung cancer. Cancer Sci. 2003; 94(1):50-56. 
14. Moscatello DK, Holgado-Madruga M, Godwin AK, et al. Frequent expression of a mutant epidermal growth factor receptor in multiple human tumors. Cancer Res. 1995;55(23):5536-5539.

15. EkstrandAJ, James CD, Cavenee WK, Seliger B, Pettersson RF, Collins VP. Genes for epidermal growth factor receptor, transforming growth factor alpha, and epidermal growth factor and their expression in human gliomas in vivo. Cancer Res. 1991;51(8):2164-2172.

16. Liu L, Backlund LM, Nilsson BR, et al. Clinical significance of EGFR amplification and the aberrant EGFRvIII transcript in conventionally treated astrocytic gliomas. J Mol Med (Berl). 2005;83(11): 917-926.

17. Kleihues P, Ohgaki H. Primary and secondary glioblastomas: from concept to clinical diagnosis. Neuro Oncol. 1999;1(1):44-51.

18. Ohgaki H, Kleihues P. Genetic pathways to primary and secondary glioblastoma. Am J Pathol. 2007;170(5):1445-1453.

19. Heimberger AB, Suki D, Yang D, Shi W, Aldape K. The natural history of EGFR and EGFRvIII in glioblastoma patients. J Transl Med. 2005;3:38.

20. Libermann TA, Nusbaum HR, Razon N, et al. Amplification, enhanced expression and possible rearrangement of EGF receptor gene in primary human brain tumours of glial origin. Nature. 1985;313(5998):144-147.

21. Bigner SH, Humphrey PA, Wong AJ, et al. Characterization of the epidermal growth factor receptor in human glioma cell lines and xenografts. Cancer Res. 1990;50(24):8017-8022.

22. Batra SK, Castelino-Prabhu S, Wikstrand CJ, et al. Epidermal growth factor ligand-independent, unregulated, cell-transforming potential of a naturally occurring human mutant EGFRvIII gene. Cell Growth Differ. 1995;6(10):1251-1259.

23. Nishikawa R, Ji XD, Harmon RC, et al. A mutant epidermal growth factor receptor common in human glioma confers enhanced tumorigenicity. Proc Natl Acad Sci U S A. 1994;91(16):7727-7731.

24. Boockvar JA, Kapitonov D, Kapoor G, et al. Constitutive EGFR signaling confers a motile phenotype to neural stem cells. Mol Cell Neurosci. 2003;24(4):1116-1130.

25. Lammering G, Hewit TH, Holmes M, et al. Inhibition of the type III epidermal growth factor receptor variant mutant receptor by dominantnegative EGFR-CD533 enhances malignant glioma cell radiosensitivity. Clin Cancer Res. 2004;10(19):6732-6743.

26. Montgomery RB, Guzman J, O’Rourke DM, Stahl WL. Expression of oncogenic epidermal growth factor receptor family kinases induces paclitaxel resistance and alters beta-tubulin isotype expression. $J$ Biol Chem. 2000;275(23):17358-17363.

27. Lammering G, Hewit TH, Valerie K, et al. EGFRvIII-mediated radioresistance through a strong cytoprotective response. Oncogene. 2003;22(36):5545-5553.

28. Moscatello DK, Ramirez G, Wong AJ. A naturally occurring mutant human epidermal growth factor receptor as a target for peptide vaccine immunotherapy of tumors. Cancer Res. 1997;57(8):1419-1424.

29. Heimberger AB, Sun W, Hussain SF, et al. Immunological responses in a patient with glioblastoma multiforme treated with sequential courses of temozolomide and immunotherapy: case study. Neuro Oncol. 2008 10(1):98-103.

30. Sharpe AH, Abbas AK. T-cell costimulation - biology, therapeutic potential, and challenges. N Engl J Med. 2006;355(10):973-975.

31. Medawar PB. Immunity to homologous grafted skin; the fate of skin homografts transplanted to the brain, to subcutaneous tissue, and to the anterior chamber of the eye. Br J Exper Pathol. 1948;29(1): 58-69.

32. Carson MJ, Doose JM, Melchior B, Schmid CD, Ploix CC. CNS immune privilege: hiding in plain sight. Immunol Rev. 2006;213:48-65.

33. Hart DN, Fabre JW. Demonstration and characterization of Ia-positive dendritic cells in the interstitial connective tissues of rat heart and other tissues, but not brain. J Exper Med. 1981;154(2):347-361.

34. Goldmann J, Kwidzinski E, Brandt C, Mahlo J, Richter D, Bechmann I. $\mathrm{T}$ cells traffic from brain to cervical lymph nodes via the cribroid plate and the nasal mucosa. J Leukocyte Biol. 2006;80(4):797-801.

35. Cserr HF, Knopf PM. Cervical lymphatics, the blood-brain barrier and the immunoreactivity of the brain: a new view. Immunol Today. 1992; 13(12):507-512.
36. de Vos AF, van Meurs M, Brok HP, et al. Transfer of central nervous system autoantigens and presentation in secondary lymphoid organs. J Immunol. 2002;169(10):5415-5423.

37. Hickey WF. Migration of hematogenous cells through the blood-brain barrier and the initiation of CNS inflammation. Brain Pathol. 1991;1(2): 97-105.

38. Engelhardt B, Ransohoff RM. The ins and outs of T-lymphocyte trafficking to the CNS: anatomical sites and molecular mechanisms. Trends Immunol. 2005;26(9):485-495.

39. Bechmann I, Priller J, Kovac A, et al. Immune surveillance of mouse brain perivascular spaces by blood-borne macrophages. Eur JNeurosci. 2001;14(10):1651-1658.

40. Lo D, Feng L, Li L, et al. Integrating innate and adaptive immunity in the whole animal. Immunol Rev. 1999;169:225-239.

41. Deli MA, Abraham CS, Kataoka Y, Niwa M. Permeability studies on in vitro blood-brain barrier models: physiology, pathology, and pharmacology. Cell Mol Neurobiol. 2005;25(1):59-127.

42. Stoll G, Jander S, Schroeter M. Detrimental and beneficial effects of injury-induced inflammation and cytokine expression in the nervous system. Adv Exper Med Biol. 2002;513:87-113.

43. Wolburg H, Wolburg-Buchholz K, Engelhardt B. Diapedesis of mononuclear cells across cerebral venules during experimental autoimmune encephalomyelitis leaves tight junctions intact. Acta Neuropathol. 2005;109(2):181-190.

44. Carman CV, Springer TA. A transmigratory cup in leukocyte diapedesis both through individual vascular endothelial cells and between them. $J$ Cell Biol. 2004;167(2):377-388.

45. Millan J, Hewlett L, Glyn M, Toomre D, Clark P, Ridley AJ. Lymphocyte transcellular migration occurs through recruitment of endothelial ICAM-1 to caveola- and F-actin-rich domains. Nature Cell biol. 2006;8(2):113-123.

46. Ransohoff RM, Kivisakk P, Kidd G. Three or more routes for leukocyte migration into the central nervous system. Nature Rev Immunol. 2003; 3(7):569-581.

47. Loeffler C, Dietz K, Schleich A, et al. Immune surveillance of the normal human CNS takes place in dependence of the locoregional blood-brain barrier configuration and is mainly performed by CD3(+)/ CD8(+) lymphocytes. Neuropathol. 2011;31(3):230-238.

48. Hussain SF, Heimberger AB. Immunotherapy for human glioma: innovative approaches and recent results. Expert Rev Anticancer Ther. 2005;5(5):777-790.

49. Serot JM, Foliguet B, Bene MC, Faure GC. Ultrastructural and immunohistological evidence for dendritic-like cells within human choroid plexus epithelium. Neuroreport. 1997;8(8):1995-1998.

50. Yang I, Han SJ, Kaur G, Crane C, Parsa AT. The role of microglia in central nervous system immunity and glioma immunology. J Clin Neurosci. 2010;17(1):6-10.

51. Mittelbronn M, Dietz K, Schluesener HJ, Meyermann R. Local distribution of microglia in the normal adult human central nervous system differs by up to one order of magnitude. Acta Neuropathol. 2001;101(3):249-255.

52. Waziri A. Glioblastoma-derived mechanisms of systemic immunosuppression. Neurosurg Clin N Am. 2010;21(1):31-42.

53. Dix AR, Brooks WH, Roszman TL, Morford LA. Immune defects observed in patients with primary malignant brain tumors. J Neuroimmunol. 1999;100(1-2):216-232.

54. Menzies CB, Gunar M, Thomas DG, Behan PO. Impaired thymusderived lymphocyte function in patients with malignant brain tumour. Clin Neurol Neurosurg. 1980;82(3):157-168.

55. Brooks WH, Roszman TL, Rogers AS. Impairment of rosette-forming $\mathrm{T}$ lymphocytes in patients with primary intracranial tumors. Cancer. 1976;37(4):1869-1873.

56. Thomas DG, Lannigan CB, Behan PO. Letter: Impaired cellmediated immunity in human brain tumours. Lancet. 1975;1(7921): 1389-1390.

57. Albesiano E, Han JE, Lim M. Mechanisms of local immunoresistance in glioma. Neurosurg Clin N Am. 2010;21(1):17-29. 
58. Dong H, Strome SE, Salomao DR, et al. Tumor-associated B7-H1 promotes T-cell apoptosis: a potential mechanism of immune evasion. Nat Med. 2002;8(8):793-800.

59. Wei J, Barr J, Kong LY, et al. Glioma-associated cancer-initiating cells induce immunosuppression. Clin Cancer Res. 2010;16(2):461-473.

60. Wiendl H, Mitsdoerffer M, Hofmeister V, et al. A functional role of HLA-G expression in human gliomas: an alternative strategy of immune escape. J Immunol. 2002;168(9):4772-4780.

61. Wischhusen J, Jung G, Radovanovic I, et al. Identification of CD70mediated apoptosis of immune effector cells as a novel immune escape pathway of human glioblastoma. Cancer Res. 2002;62(9):2592-2599.

62. Fecci PE, Mitchell DA, Whitesides JF, et al. Increased regulatory T-cell fraction amidst a diminished CD4 compartment explains cellular immune defects in patients with malignant glioma. Cancer Res. 2006;66(6):3294-3302.

63. Jordan JT, Sun W, Hussain SF, DeAngulo G, Prabhu SS, Heimberger AB. Preferential migration of regulatory $\mathrm{T}$ cells mediated by glioma-secreted chemokines can be blocked with chemotherapy. Cancer Immunol Immunother. 2008;57(1):123-131.

64. Thornton AM, Shevach EM. CD4+CD25+ immunoregulatory T cells suppress polyclonal $\mathrm{T}$ cell activation in vitro by inhibiting interleukin 2 production. J Exper Med. 1998;188(2):287-296.

65. Dieckmann D, Plottner H, Berchtold S, Berger T, Schuler G. Ex vivo isolation and characterization of CD4(+)CD25(+) T cells with regulatory properties from human blood. J Exper Med. 2001;193(11): 1303-1310

66. Carpenter G, Cohen S. Epidermal growth factor. J Biol Chem. 1990;265(14):7709-7712.

67. Shinojima N, Tada K, Shiraishi S, et al. Prognostic value of epidermal growth factor receptor in patients with glioblastoma multiforme. Cancer Res. 2003;63(20):6962-6970.

68. Sauter G, Maeda T, Waldman FM, Davis RL, Feuerstein BG. Patterns of epidermal growth factor receptor amplification in malignant gliomas. Am J Pathol. 1996;148(4):1047-1053.

69. Malden LT, Novak U, Kaye AH, Burgess AW. Selective amplification of the cytoplasmic domain of the epidermal growth factor receptor gene in glioblastoma multiforme. Cancer Res. 1988;48(10):2711-2714.

70. Ekstrand AJ, Sugawa N, James CD, Collins VP. Amplified and rearranged epidermal growth factor receptor genes in human glioblastomas reveal deletions of sequences encoding portions of the $\mathrm{N}$ - and/or C-terminal tails. Proc Natl Acad Sci U S A. 1992;89(10):4309-4313.

71. Yamazaki H, Fukui Y, Ueyama Y, et al. Amplification of the structurally and functionally altered epidermal growth factor receptor gene (c-erbB) in human brain tumors. Mol Cell Biol. 1988;8(4):1816-1820.

72. Sugawa N, Ekstrand AJ, James CD, Collins VP. Identical splicing of aberrant epidermal growth factor receptor transcripts from amplified rearranged genes in human glioblastomas. Proc Natl Acad Sci U S A. 1990;87(21):8602-8606.

73. Kuan CT, Wikstrand CJ, Bigner DD. EGF mutant receptor vIII as a molecular target in cancer therapy. Endocr Relat Cancer. 2001;8(2): 83-96.

74. Pedersen MW, Tkach V, Pedersen N, Berezin V, Poulsen HS. Expression of a naturally occurring constitutively active variant of the epidermal growth factor receptor in mouse fibroblasts increases motility. Int J Cancer. 2004;108(5):643-653.

75. Nagane M, Coufal F, Lin H, Bogler O, Cavenee WK, Huang HJ. A common mutant epidermal growth factor receptor confers enhanced tumorigenicity on human glioblastoma cells by increasing proliferation and reducing apoptosis. Cancer Res. 1996;56(21):5079-5086.

76. Wikstrand CJ, McLendon RE, Friedman AH, Bigner DD. Cell surface localization and density of the tumor-associated variant of the epidermal growth factor receptor, EGFRvIII. Cancer Res. 1997;57(18): 4130-4140.

77. Al-Nedawi K, Meehan B, Micallef J, et al. Intercellular transfer of the oncogenic receptor EGFRvIII by microvesicles derived from tumour cells. Nat Cell Biol. 2008;10(5):619-624.
78. Klausz K, Berger S, Lammerts van Bueren JJ, et al. Complementmediated tumor-specific cell lysis by antibody combinations targeting epidermal growth factor receptor (EGFR) and its variant III (EGFRvIII). Cancer Sci. 2011;102(10):1761-1768.

79. Gupta P, Han SY, Holgado-Madruga M, et al. Development of an EGFRvIII specific recombinant antibody. BMC Biotechnol. 2010;10:72.

80. Jiang H, Wang H, Tan Z, et al. Growth suppression of human hepatocellular carcinoma xenografts by a monoclonal antibody $\mathrm{CH} 12$ directed to epidermal growth factor receptor variant III. J Biol Chem. 2011;286(7):5913-5920.

81. Scott AM, Lee FT, Tebbutt N, et al. A phase I clinical trial with monoclonal antibody ch806 targeting transitional state and mutant epidermal growth factor receptors. Proc Natl Acad Sci U S A. 2007; 104(10):4071-4076.

82. Sampson JH, Crotty LE, Lee S, et al. Unarmed, tumor-specific monoclonal antibody effectively treats brain tumors. Proc Natl Acad Sci US A. 2000;97(13):7503-7508.

83. Lorimer IA, Wikstrand CJ, Batra SK, Bigner DD, Pastan I. Immunotoxins that target an oncogenic mutant epidermal growth factor receptor expressed in human tumors. Clin Cancer Res. 1995;1(8):859-864.

84. Archer GE, Sampson JH, Lorimer IA, et al. Regional treatment of epidermal growth factor receptor vIII-expressing neoplastic meningitis with a singlechain immunotoxin, MR-1. Clin Cancer Res. 1999;5(9): 2646-2652.

85. Sampson JH, Archer GE, Mitchell DA, Heimberger AB, Bigner DD. Tumor-specific immunotherapy targeting the EGFRvIII mutation in patients with malignant glioma. Semin Immunol. 2008;20(5): 267-275.

86. Bullain SS, Sahin A, Szentirmai O, et al. Genetically engineered T cells to target EGFRvIII expressing glioblastoma. JNeurooncol. 2009;94(3): 373-382.

87. Sampson JH, Archer GE, Mitchell DA, et al. An epidermal growth factor receptor variant III-targeted vaccine is safe and immunogenic in patients with glioblastoma multiforme. Mol Cancer Ther. 2009;8(10): 2773-2779.

88. Sampson JH, Heimberger AB, Archer GE, et al. Immunologic escape after prolonged progression-free survival with epidermal growth factor receptor variant III peptide vaccination in patients with newly diagnosed glioblastoma. J Clin Oncol. 2010;28(31):4722-4729.

89. Heimberger AB, Crotty LE, Archer GE, et al. Epidermal growth factor receptor VIII peptide vaccination is efficacious against established intracerebral tumors. Clin Cancer Res. 2003;9(11):4247-4254.

90. Aldape KD, Ballman K, Furth A, et al. Immunohistochemical detection of EGFRvIII in high malignancy grade astrocytomas and evaluation of prognostic significance. J Neuropathol Exper Neurol. 2004;63(7): 700-707.

91. Yoshimoto K, Dang J, Zhu S, et al. Development of a real-time RT-PCR assay for detecting EGFRvIII in glioblastoma samples. Clin Cancer Res. 2008;14(2):488-493.

92. Heimberger AB, Archer GE, Crotty LE, et al. Dendritic cells pulsed with a tumor-specific peptide induce long-lasting immunity and are effective against murine intracerebral melanoma. Neurosurgery. 2002; 50(1):158-164; discussion 164-166.

93. Curran WJ Jr, Scott CB, Horton J, et al. Recursive partitioning analysis of prognostic factors in three Radiation Therapy Oncology Group malignant glioma trials. J Natl Cancer Inst. 1993;85(9):704-710.

94. Sampson JH, Aldape KD, Archer GE, et al. Greater chemotherapyinduced lymphopenia enhances tumor-specific immune responses that eliminate EGFRvIII-expressing tumor cells in patients with glioblastoma. Neuro Oncol. 2011;13(3):324-333.

95. Lai RK, Recht LD, Reardon DA, et al. Long-term follow-up of ACT III: A Phase II trial of rindopepimut (CDX-110) in newly diagnosed glioblastoma. Abstract IM-03. SNO: 16th Annual Scientific Meeting of the Society for Neuro-Oncology in Conjunction with the AANS/CNS Section on Tumors; November 17-20, 2011; Orange County, CA. Neuro Oncol. 2011;13(Suppl 3): iii34-iii40.

96. Yan H, Parsons DW, Jin G, et al. IDH1 and IDH2 mutations in gliomas. N Engl J Med. 2009;360(8):765-773. 
97. Nobusawa S, Watanabe T, Kleihues P, Ohgaki H. IDH1 mutations as molecular signature and predictive factor of secondary glioblastomas. Clin Cancer Res. 2009;15(19):6002-6007.
98. SongTao Q, Lei Y, Si G, et al. IDH mutations predict longer survival and response to temozolomide in secondary glioblastoma. Cancer Sci. 2012;103(2):269-273.

\section{Core Evidence}

\section{Publish your work in this journal}

Core Evidence is an international, peer-reviewed open-access journal evaluating the evidence underlying the potential place in therapy of drugs throughout their development lifecycle from preclinical to postlaunch. The focus of each review is to evaluate the case for a new drug or class in outcome terms in specific indications and patient groups

Submit your manuscript here: http://www.dovepress.com/core-evidence-journal

\section{Dovepress}

The manuscript management system is completely online and includes a very quick and fair peer-review system, which is all easy to use. Visit http://www.dovepress.com/testimonials.php to read real quotes from published authors. 